CASE REPORT

\title{
Treatment with epoprostenol of pulmonary arterial hypertension following mitral valve replacement for mitral stenosis
}

\author{
C G Elliott, H I Palevsky
}

Thorax 2004;59:536-537. doi: 10.1136/thx.2003.008193

Pulmonary hypertension frequently complicates mitral stenosis. Increased pulmonary artery pressure results from raised left atrial pressure, pulmonary arteriolar constriction, and obliterative changes in the pulmonary vascular bed, and usually responds to surgical relief of mitral stenosis. However, severe pulmonary hypertension may persist after surgical treatment of mitral stenosis. We describe a patient whose severe pulmonary hypertension following mitral valve replacement was treated successfully with continuous intravenous epoprostenol.

$\mathrm{E}$ poprostenol was first introduced for the treatment of primary pulmonary hypertension in $1984 .{ }^{1}$ Subsequent investigations showed that continuous intravenous administration of epoprostenol provided effective treatment for pulmonary arterial hypertension related to the CREST variant of systemic sclerosis, human immunodeficiency virus infection, and portopulmonary hypertension. These observations expanded the use of epoprostenol to patients with pulmonary arterial hypertension, but the use of epoprostenol to treat pulmonary hypertension associated with surgically corrected mitral stenosis has not been described.

\section{CASE REPORT}

A 46 year old woman, diagnosed at the age of 11 with acute rheumatic fever, underwent placement of a \#26 Duran ring for mitral regurgitation in 1991. Pulmonary artery pressures were normal although mild mitral stenosis was noted postoperatively. She was lost to follow up.

In 1999 she sought medical attention because of dyspnoea and orthopnoea. Cardiac catheterisation showed severe pulmonary hypertension (mean pulmonary artery pressure $48 \mathrm{~mm} \mathrm{Hg}$ ) with a $14 \mathrm{~mm} \mathrm{Hg}$ gradient across the mitral valve (pulmonary capillary wedge pressure $18 \mathrm{~mm} \mathrm{Hg}$ ). In August 1999 she underwent mitral valve replacement with a $23 \mathrm{~mm}$ St Jude prosthesis. Postoperative transoesophageal echocardiography showed good function of the new prosthetic valve, but severe pulmonary hypertension persisted.

In June 2001 she again sought medical attention because of dyspnoea with the slightest activity. Echocardiography showed a normally functioning prosthetic mitral valve and severe pulmonary hypertension. Diagnostic workup did not suggest another aetiology for pulmonary hypertension. Cardiac catheterisation showed severe pulmonary hypertension without evidence of mitral stenosis (table 1). Continuous intravenous epoprostenol (Flolan) was begun. Over the next 4 months the dose was increased from $7 \mathrm{ng} / \mathrm{kg} /$ min to $23 \mathrm{ng} / \mathrm{kg} / \mathrm{min}$ and the patient noted improvement in her exercise capacity. Six and 17 months after beginning epoprostenol repeat right heart catheterisation showed significant and sustained reductions of pulmonary artery pressure and pulmonary vascular resistance (table 1).

\section{DISCUSSION}

Pulmonary hypertension is a common complication of severe mitral valve disease. ${ }^{2}{ }^{3}$ Raised pulmonary artery pressure results initially from increased left atrial pressure, pulmonary arteriolar vasoconstriction, and ultimately obliterative changes in the pulmonary vascular bed. Wood ${ }^{4}$ studied 500 cases of critical mitral stenosis, $12 \%$ of whom had extremely high pulmonary vascular resistance ( $>10$ units) and $16 \%$ in whom it was moderately high (6-10 units). Injection of $1 \mathrm{mg}$ acetylcholine lowered pulmonary artery pressures in 14 of 16 cases, but in two cases with extremely high pulmonary vascular resistance there was no response, presumably because of obliterative pulmonary vascular disease.

Mitral valve replacement generally alleviates pulmonary hypertension, ${ }^{23}$ but a small subgroup of patients have persistent severe pulmonary hypertension in spite of relief of mitral stenosis by closed valvuloplasty ${ }^{5}$ or mitral valve replacement. $^{23}$ Other patients with extreme preoperative increases in pulmonary vascular resistance do not survive valvuloplasty or valve replacement because of pulmonary vascular disease. Failure to respond to surgical relief of mitral stenosis often reflects pathological changes in the pulmonary arteries that resemble those seen with other causes of pulmonary arterial hypertension. ${ }^{6}$ Excessive thickening of the media and intimal fibrosis of small muscular pulmonary arteries are typical of long standing mitral

Table 1 Haemodynamic variables 2 years after mitral valve replacement (baseline) and after long term epoprostenol treatment

\begin{tabular}{|c|c|c|c|}
\hline & \multirow[b]{2}{*}{ Baseline } & \multicolumn{2}{|c|}{ Epoprostenol } \\
\hline & & 6 months* & 17 months $\uparrow$ \\
\hline $\begin{array}{l}\text { Mean systemic arterial } \\
\text { pressure }(\mathrm{mm} \mathrm{Hg})\end{array}$ & 83 & 83 & 90 \\
\hline $\begin{array}{l}\text { Mean right atrial pressure } \\
\text { (mm Hg) }\end{array}$ & 12 & 16 & 16 \\
\hline $\begin{array}{l}\text { Mean pulmonary artery } \\
\text { pressure }(\mathrm{mm} \mathrm{Hg})\end{array}$ & 65 & 55 & 57 \\
\hline Cardiac output (l/min) & 2.2 & 2.9 & 3.2 \\
\hline $\begin{array}{l}\text { Pulmonary artery occlusion } \\
\text { pressure }(\mathrm{mm} \mathrm{Hg})\end{array}$ & 12 & $16 \ddagger$ & $18 \ddagger$ \\
\hline $\begin{array}{l}\text { Left ventricular end diastolic } \\
\text { pressure }(\mathrm{mm} \mathrm{Hg})\end{array}$ & 12 & 7 & - \\
\hline $\begin{array}{l}\text { Pulmonary vascular } \\
\text { resistance }\left(\text { dyne. } / \mathrm{cm}^{5}\right)\end{array}$ & 1560 & 1072 & 999 \\
\hline
\end{tabular}

*Epoprostenol dose $24 \mathrm{ng} / \mathrm{kg} / \mathrm{min}$.

†Epoprostenol dose $26 \mathrm{ng} / \mathrm{kg} / \mathrm{min}$

$\mp$ Thrombosis of the anterior leaflet of the St Jude valve led to mild

increases in pulmonary artery occlusion pressure at 6 months and

17 months after epoprostenol was started. 
stenosis as well as other conditions associated with severe pulmonary hypertension. ${ }^{6}$

Mitral stenosis rarely coexists with primary pulmonary hypertension. ${ }^{7}$ The distinction between pulmonary hypertension complicating mitral stenosis and primary pulmonary hypertension is difficult, particularly when the pulmonary artery wedge pressure is only modestly raised. ${ }^{89}$ Sometimes there are clues-such as the identification of another family member with primary pulmonary hypertension ${ }^{7}$ - which help to distinguish these two conditions but, in spite of a careful search, we were unable to identify such a clue in this case. We cannot exclude the possibility that the patient represents the extremely unusual coexistence of primary pulmonary hypertension with mitral stenosis, although this possibility seems less likely in the setting of established mitral stenosis.

The present case illustrates a favourable response to epoprostenol of a patient with severe pulmonary hypertension following successful mitral valve replacement. Epoprostenol improves survival as well as haemodynamics in primary pulmonary hypertension, ${ }^{10}$ although the exact mechanism for this effect remains uncertain. The haemodynamic response of our patient was typical of the response described for patients with primary pulmonary hypertension, ${ }^{10}$ and suggests that epoprostenol may have a role in the treatment of patients with sustained pulmonary hypertension after successful mitral valve replacement.

\section{Authors' affiliations}

C G Elliott, Departments of Medicine, Pulmonary and Critical Care Divisions, LDS Hospital and the University of Utah School of Medicine, Salt Lake City, USA
H I Palevsky, Department of Medicine, Pulmonary and Critical Care Division, Presbyterian Medical Center, University of Pennsylvania Health System, USA

Correspondence to: Professor C G Elliott, Pulmonary Division, LDS Hospital, Salt Lake City, UT 84143; Idgellio@ihc.com

Received 11 April 2003

Accepted 14 August 2003

\section{REFERENCES}

1 Higenbottam $T$, Wheeldon $D$, Wells $F$, et al. Long-term treatment of primary pulmonary hypertension with continuous intravenous epoprostenol (prostacyclin). Lancet 1984; 1:1046-7.

2 Dalen JE, Matloff JM, Evans GL, et al. Early reduction of pulmonary vascular resistance after mitral-valve replacement. N Engl J Med 1967:277:387-94.

3 Braunwald E, Braunwald NS, Ross J, et al. Effects of mitral-valve replacement on the pulmonary vascular dynamics of patients with pulmonary hypertension. N Engl J Med 1965;273:509-14.

4 Wood P. The vasoconstrictive factor in pulmonary hypertension. In: Adams WR, Veith I, eds. Pulmonary circulation: an international symposium. New York: Grune, 1959:294-301.

5 Likoff W. Change in pulmonary vascular resistance after relief of mitral obstruction. In: Adams WR, Veith I, eds. Pulmonary circulation: an international symposium. New York: Grune, 1959:302-10.

6 Tandon HD, Kasturi J. Pulmonary vascular changes associated with isolated mitral stenosis in India. Br Heart $J$ 1975;37:26-36.

7 Langleben D, Lamourex E, Marcotte F, et al. Mitral stenosis obscuring the diagnosis of plexigenic pulmonary arteriopathy and familial pulmonary hypertension. Thorax 2000;55:247-8.

8 Cheng TO. Differentiation between mitral stenosis and coexisting primary pulmonary hypertension. Thorax 2000;55:807.

9 Langleben D, Schlesinger R. Differentiation between mitral stenosis and coexisting primary pulmonary hypertension: authors' reply. Thorax 2000;55:807

10 Mclaughlin VV, Genthner DE, Panella MM, et al. Reduction in pulmonary vascular resistance with long-term epoprostenol (prostacyclin) therapy in primary pulmonary hypertension. N Engl J Med 1998;338:273-7.

\section{LUNG ALERT}

Does a raised pro-BNP level in pleural fluid aid the diagnosis of effusion due to heart failure?

$\Delta$ Porcel JM, Vives M, Cao G, et al. Measurement of pro-brain natriuretic peptide in pleural fluid for the diagnosis of pleural effusions due to heart failure. Am J Med 2004;116:417-20.

$\mathrm{P}$ lasma levels of B-type natriuretic peptide (BNP) are increased in heart failure. The aim of this study was to assess the usefulness of BNP measurements in pleural fluid from patients with and without heart failure. The pro-BNP concentration was measured in 117 pleural fluid samples taken from patients with heart failure, malignant effusions, tuberculous pleurisy, parapneumonic effusions, hepatic hydrothorax, and effusions secondary to pulmonary embolism. In patients with heart failure the median level of proBNP was significantly higher than in all other groups $(\mathrm{p}<0.001)$. A pleural fluid BNP concentration of $\geqslant 1500 \mathrm{pg} / \mathrm{ml}$ had a sensitivity of $91 \%$ and specificity of $93 \%$ for the diagnosis of cardiac failure and, furthermore, a high pro-BNP level helped to correctly identify those heart failure patients, mostly on diuretics, who were classed as having exudates according to Light's criteria.

There are, however, limitations to the study. It is not reported whether pro-BNP levels were more predictive of heart failure than clinical variables such as a history of myocardial infarction, and it did not compare the pleural pro-BNP concentration with plasma BNP levels. Further studies are required to clarify the clinical usefulness of pleural fluid BNP assay.

Z Hall 